\title{
The acute effect of static stretching between sets on the number of repetitions performance in resistance training
}

\author{
Erbil Murat Aydın ${ }^{1}$ \\ Yilmaz Uçan ${ }^{2}$ \\ Hakan Yarar ${ }^{3}$
}

\begin{abstract}
Rest interval between sets in resistance exercises is an important variable that influence on the training volume. The purpose of the current study was to determine the effect of static stretching on the number of repetitions for three consecutive sets upper and lower body exercises. Nine

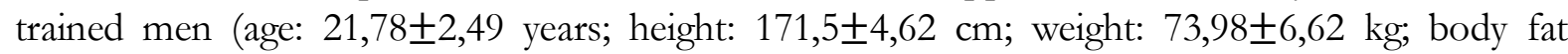
percentage: $11,1 \pm 3,95 \%$ ) completed three sets push down and leg extension exercises with 10 repetition maximum, $\% 60$ of 1 repetition maximum and \%85 of 1 repetition maximum load. Participants took part static stretching and non-stretching conditions that was done on counterbalance. The results of this study demonstrated that the number of repetitions significantly decreased after static stretching for both exercises at all intensities. When compared the two conditions, the number of repetitions after static stretching on set 2 and set 3 was significantly lower than the set 1 for push down exercise at all intensities. However, for leg extension exercise at 10 repetition maximum intensity on set 2 was significantly lower than the set 1 and at $\% 85$ of 1 repetition maximum intensity on set 2 and set 3 significantly lower than the set 1 . There is no significant difference for leg extension exercise between groups at $\% 60$ of 1 repetition maximum intensity. In conclusion, this study indicated that static stretching between consecutive sets has negative effect on the number of repetitions for push down and leg extension exercises. Therefore static stretching should be avoided during the rest period between sets when performing the push down and leg extension exercises.
\end{abstract}

Keywords: Rest interval; active rest; stretching exercise; resistance exercises; upper body; lower body.

\section{Introduction}

Resistance exercises are commonly used to improve muscular strength, power and endurance. Designing appropriate program to achieve goals of resistance training is the most important factor (Kraemer and Ratamess, 2004). Resistance trainings contain several variables such as intensity, frequency, volume, rest intervals (ACSM, 2011; Schoenfeld et al., 2014). Performing multiple set is more effective than single set for strength gain in resistance exercise training (Rhea et

\footnotetext{
${ }^{1}$ Res. Asst., Abant Izzet Baysal University, School of Physical Education and Sports, Department of Coaching Education, emurataydin@ibu.edu.tr

2 Asst. Prof., Abant Izzet Baysal University, School of Physical Education and Sports, Department of Coaching Education, mr ucan@hotmail.com

${ }^{3}$ Asst. Prof., Abant Izzet Baysal University, School of Physical Education and Sports, Department of Coaching Education, hakanyarar96@,hotmail.com
} 
Aydın, E. M., Uçan, Y., \& Yarar, H. (2017). The acute effect of static stretching between sets on the number of repetitions performance in resistance training. Journal of Human Sciences, 14(4), 3913-3922. doi:10.14687/jhs.v14i4.4865

al., 2002). Resting interval variable between sets is the important for multiple set exercises. Previous studies reported effects of different duration and activities in rest interval between sets on performance (Arazi et al., 2015; Blazquez et al., 2013; Evangelista et al., 2011; García-López et al., 2007; García-López et al., 2010; Hill-Haas et al., 2007; Miranda et al., 2007; Nasiri et al., 2011; Rahimi, 2005; Ramírez-Campillo et al., 2014; Ratamess et al., 2007; Richmond and Godard, 2004; Rodrigues et al., 2010; Senna et al., 2009; Silva et al., 2010; Souza et al., 2013; Willardson and Burkett, 2005; Willardson and Burkett, 2006a; Willardson and Burkett, 2006b; Willardson and Burkett, 2008). Some studies showed hormonal responses on different rest durations between sets (Ahtiainen et al., 2005; Boroujerdi and Rahimi, 2008; Bottaro et al., 2009; Buresh et al., 2009; Rahimi et al., 2010). Studies mentioned above reported effects of rest interval length between 30 seconds (s) to 5 minutes ( $\mathrm{min}$ ) for different exercises with different intensities. Evangelista et al. (2011) studied the effects of two different rest lengths on total workout volume, number of repetitions, muscle damage and muscle soreness. According to results of this study 3 min rest between sets provide greater number of repetitions than 1 min rest in the second set for $\% 40$ of maximum voluntary contraction intensity biceps curl exercise. Willardson and Burkett (2005) reported that $5 \mathrm{~min}$ rest between sets resulted in higher volume completed than $1 \mathrm{~min}$ and $3 \mathrm{~min}$ rest for squat and bench press exercises with 8 repetition maximum (RM) load. Rahimi (2005) reported the $5 \mathrm{~min}$ rest interval results in higher volume completed compared to $1 \mathrm{~min}$ and $2 \mathrm{~min}$ rest interval for squat exercise at \%85 of 1RM load. Richmond and Godard (2004) investigated the effect of 1,3 and 5 min rest period for 2 sets bench press at $\% 75$ of $1 \mathrm{RM}$ load. This study indicated that there were decreases in the number of repetitions for 3 rest durations. However 8-12 repetitions range was maintained in the 3 and 5 min rest periods. Besides total work performed second set is higher for 3 and $5 \mathrm{~min}$ than $1 \mathrm{~min}$ rest period. According to studies mentioned above longer rest interval resulted in higher number of repetitions or volume completed. Type of activity between sets is also important for the resistance exercise. Lifters commonly perform stretching between sets and exercises (García-López et al., 2010). Active recovery and stretching between the consecutive sets are mostly used by athletes and coaches to diminish the effects of fatigue. Previous studies demonstrated that static stretching has negative effects on performance which performed after static stretching (Cornwell et al., 2002; Evetovich et al., 2003; Hough et al., 2009; Kistler et al., 2010; Kokkonen et al., 1998; Nelson et al., 2005; Paradisis et al., 2014; Pinto et al., 2014; Young and Behm, 2003). However, little research has reported the effects of stretching between sets on the number of repetitions or volume completed. Nasiri et al. (2011) investigated the effects of dynamic stretching between 3 consecutive sets with different rest duration on repetitions performance for bench press exercise at $\% 50$ and $\% 75$ of $1 \mathrm{RM}$ intensity in untrained men. Researcher reported that both intensities and rest durations using dynamic stretching between sets resulted in higher repetitions compared to passive rest for two intensities and two rest durations. Besides there were no differences between $3 \mathrm{~min}$ and $4 \mathrm{~min}$ rest duration for two intensities in active rest. However in passive recovery 4 min rest resulted in higher training volume rather than 3 min rest. Arazi et al. (2015) studied acute effects of two different stretching methods in the rest periods between sets on the number of repetitions for upper and lower body exercises at $\% 80$ of $1 \mathrm{RM}$ intensity. The results of their study showed that in $3 \mathrm{~min}$ and 5 min rest interval, the number of repetitions decreased throughout the 3 set after the first set. However there were no significant differences between static, dynamic and non-stretching conditions. Static stretching exercises between consecutive sets are mostly used by athletes. However few studies have reported the effects of interset static stretching on the number of repetitions. Therefore, the purpose of present study was to examine the acute effects of static stretching between sets on the number of repetitions for upper and lower body exercises at different intensities. 
Aydın, E. M., Uçan, Y., \& Yarar, H. (2017). The acute effect of static stretching between sets on the number of repetitions performance in resistance training. Journal of Human Sciences, 14(4), 3913-3922. doi:10.14687/jhs.v14i4.4865

\section{Methods}

\subsection{Subjects}

9 male (age: $21,78 \pm 2,49$ years; height: $171,5 \pm 4,62 \mathrm{~cm}$; weight: 73,98 $\pm 6,62 \mathrm{~kg}$; body fat percentage: $11,1 \pm 3,95 \%$ ) trained subjects who have been doing strength training regularly for last 1 year participated in the study. Approval for this study was obtained from Ethical Committee of Abant Izzet Baysal University (Decision No: 2016/66). All participants informed about procedures and participants signed consent form before participation in the study. Participants were instructed to avoid intensive physical exercises throughout the study. The participants were informed about not to change their nutritional and sleep habits throughout the study.

\subsection{Experimental Protocols}

Randomized crossover design was used in this study. Information about the test protocols and test devices were given to the participants on the first session. On the same session participants were familiarized with stretching protocols, push down (PD) and leg extension (LE) exercises. Besides information about the proper technique of the exercise execution was given to the participants. Familiarization period lasted 1 week. On the second session body height, body mass and body composition measurement of participants were analyzed. Besides participants performed 10 repetition maximum (10RM) test on the same session. 10RM converted to 1 repetition maximum (1RM) value by using Brzycki (1993) equations.

$1 \mathrm{RM}=($ Weight lifted $/(1.0278-[0.0278 \times$ No. of reps $])$

After the analysis participants separated randomly two groups as non-stretching group (NS), static stretching group (SS). On the third session participants performed PD and LE exercises at 10RM intensity. On the fourth session participants performed PD and LE exercises at $\% 85$ of 1RM intensity. On the fifth session participants performed PD and LE exercises at \%60 of 1RM intensity. Participants performed PD exercise before LE exercise on the each session. Participants performed 3 sets each exercise. 3 min resting was given to the NS between sets. SS performed 2 sets and 30s each set static stretching. Static stretching lasted 2 min. SS performed static stretching last $2 \mathrm{~min}$ in $3 \mathrm{~min}$ resting period. Experimental methodology is given in Figure 1. Before performed exercises participants performed 10 min warm-up on treadmill at self-selected velocity and 1 set exercise warm-up at $\% 50$ of 10RM intensity.

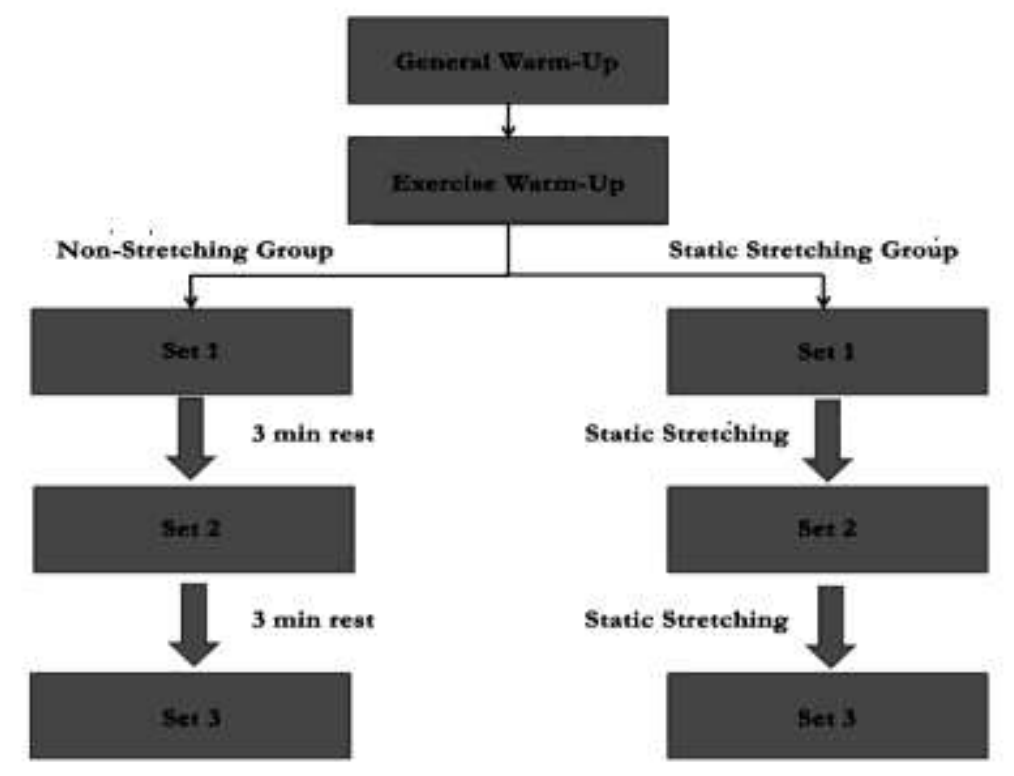

Figure 1: Experimental methodology 
Aydın, E. M., Uçan, Y., \& Yarar, H. (2017). The acute effect of static stretching between sets on the number of repetitions performance in resistance training. Journal of Human Sciences, 14(4), 3913-3922. doi:10.14687/jhs.v14i4.4865

\subsection{Measurements}

\section{Body Composition Measurement}

Foot-to-foot bioelectrical impedance analyzer (BIA) (Tanita BC-418 MA; Tanita Corp., Japan) was used to obtain the body-fat percentage (\%body fat) of the subjects. BIA measurements were carried out following the manufacturer's procedures.

\section{Maximal Strength Measurement}

10RM method was used to calculate the maximal strength. Participants performed $10 \mathrm{~min}$ warm up on treadmill before 10RM attempt. Then, they performed 1 set low intensity PD exercise. The initial load was estimated according to participants past experiences. In case the subject could not perform 10 repetitions in the first attempt, the weight was decreased 4-10 kg. If subject performed 10 repetitions, weight was increased until subject failure to perform 10 repetitions. Minimum $3 \mathrm{~min}$ rest was given between attempts. Maximum 5 trials allowed on one day. Participants were verbally motivated throughout the study periods. All tests were performed at the same time of the day.

\section{Stretching Exercises}

Static stretching exercises were performed to triceps and quadriceps muscles. Nonstretching group didn't perform any stretching exercises. Participants performed stretching exercises at mild discomfort for 30s. Stretching exercises for one leg/arm were performed 30s after that participants change the leg/arm and performed again stretching exercises. Resting wasn't given between leg/arm changes. Stretching exercises were performed 2 sets. Time was countered for each participant by same person by using digital counter. Stretching exercises were given in Figure 2.

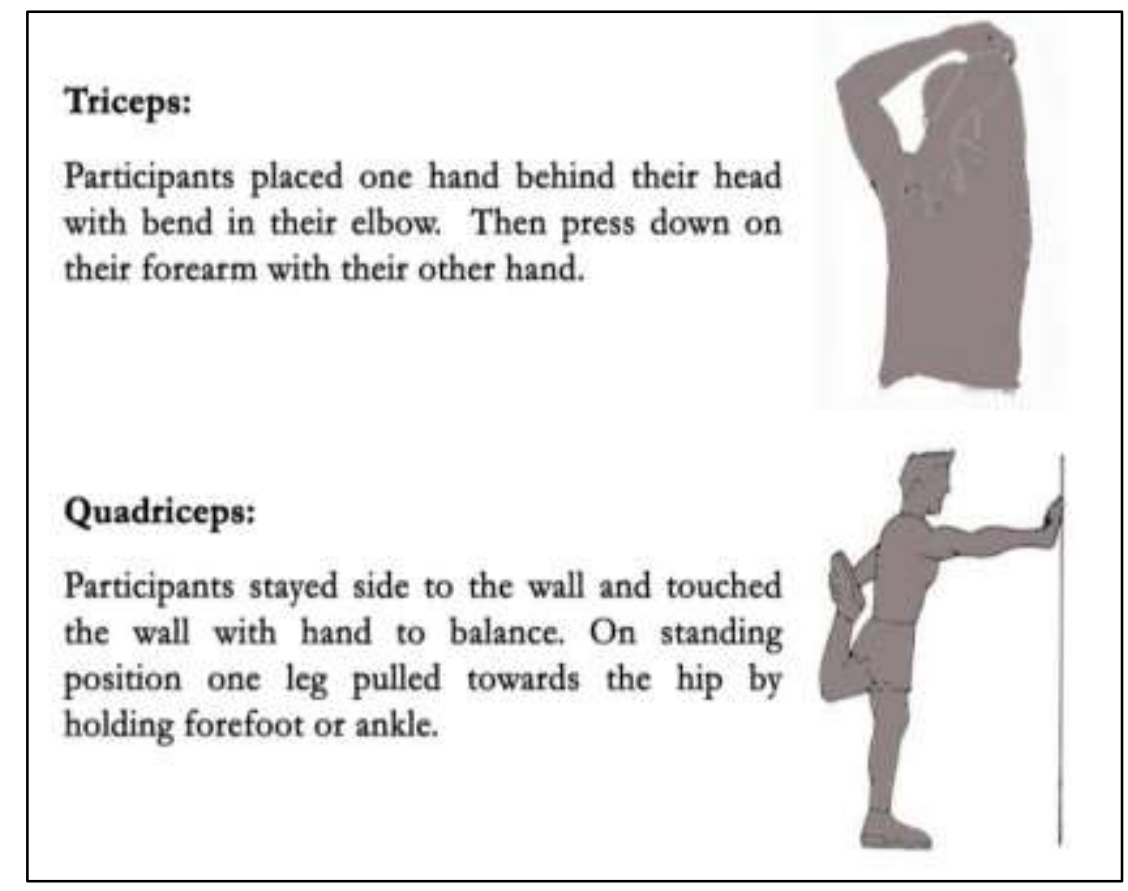

Figure 2: Static stretching exercises

\subsection{Statistical Analysis}

Data are presented as mean \pm standard deviation (SD). Before performed statistical analysis, the normal distribution of data was confirmed by Shapiro-Wilk test. According to ShapiroWilk test results, the variables presented normal distribution. The number of repetitions for PD and LE exercise was analyzed using 2 (groups) $\times 3$ (time) two way repeated measures analysis of variances. Bonferroni post-hoc test was applied to examine significant differences between pre-test 
Aydın, E. M., Uçan, Y., \& Yarar, H. (2017). The acute effect of static stretching between sets on the number of repetitions performance in resistance training. Journal of Human Sciences, 14(4), 3913-3922. doi:10.14687/jhs.v14i4.4865

and post tests for each group. Paired sample t-test was used to compare the groups. All statistical analyses were performed using SPSS 20 package program. Statistical significance level was set at $\mathrm{p}<0.05$.

\section{Results}

At $10 \mathrm{RM}$ intensity a significant main time effect was shown in the number of repetitions on sets for $\mathrm{LE}(\mathrm{F}=9,207, \mathrm{p}=0,011)$ (Table 1). There were significant group $\times$ time interactions between set 1 and set $2(p=0,016)$, set 1 and set $3(p=0,031)$ for LE. A significant main time effect was shown in the number of repetitions on sets for PD $(F=29,732, p=0,000)$ (Table 2). There were significant group $\times$ time interactions between set 1 and set $2(p=0,004)$, set 1 and set $3(p=0,007)$ for PD (Figure 3).

At $\% 60$ of $1 \mathrm{RM}$ intensity a significant main time effect was shown in the number of repetitions on sets for $\mathrm{LE}(\mathrm{F}=15,796, \mathrm{p}=0,003)$ (Table 1). No significant group $\times$ time interactions were shown for LE. A significant main time effect was shown in the number of repetitions on sets for PD $(F=56,669, p=0,000)$ (Table 2). There were significant group $\times$ time interactions between set 1 and set $2(p=0,007)$, set 1 and set $3(p=0,01)$ for PD (Figure 3$)$.

At $\% 85$ of $1 \mathrm{RM}$ intensity a significant main time effect was shown in the number of repetitions on sets for $\mathrm{LE}(\mathrm{F}=17,963, \mathrm{p}=0,000)$ (Table 1). There were significant group $\times$ time interactions between set 1 and set $2(p=0,016)$, set 1 and set $3(p=0,001)$, set 2 and set $3(p=0,05)$ for LE. A significant main time effect was shown in the number of repetitions on sets for PD $(\mathrm{F}=11,581, \mathrm{p}=0,001)$ (Table 2). There were significant group $\times$ time interactions between set 1 and set $2(p=0,006)$, set 1 and set $3(p=0,001)$ for PD (Figure 3 ).

Table 1. The numbers of repetitions of groups with different intensities for LE exercise

\begin{tabular}{|c|c|c|c|c|c|c|}
\hline Intensity & Groups & Set 1 & & Set 2 & & Set 3 \\
\hline & SS & $11,89 \pm 1,69$ & & $10,22 \pm 1,99 *$ & & $9,33 \pm 2,74^{*}$ \\
\hline \multirow[t]{4}{*}{$10 \mathrm{RM}$} & $\Delta \%$ & & 14,05 & & 8,71 & \\
\hline & NS & $11,56 \pm 1,24$ & & $11,33 \pm 1,41$ & & $10,78 \pm 1,79$ \\
\hline & $\Delta \%$ & & & 1,99 & & 4,85 \\
\hline & SS & $20,78 \pm 5,09$ & & $17,22 \pm 4,09 *$ & & $15,33 \pm 3,54^{* \#}$ \\
\hline \multirow[t]{4}{*}{$\% 60$} & $\Delta \%$ & & 17,13 & & 10,98 & \\
\hline & NS & $20,67 \pm 5,29$ & & $18,78 \pm 3,56$ & & $16,78 \pm 3,70^{* \#}$ \\
\hline & $\Delta \%$ & & & 9,14 & & 10,65 \\
\hline & SS & $9,22 \pm 2,28$ & & $7,56 \pm 2,30 *$ & & $6,67 \pm 1,80^{* \#}$ \\
\hline \multirow[t]{3}{*}{$\% 85$} & $\Delta \%$ & & 18,00 & & 11,77 & \\
\hline & NS & $8,56 \pm 1,59$ & & $8,22 \pm 1,64$ & & $8,00 \pm 1,58$ \\
\hline & $\Delta \%$ & & 3,97 & & 2,68 & \\
\hline
\end{tabular}

$\Delta \%$ percent change from the previous set

* There is significant difference according to Set $1(p<0,05)$

\#There is significant difference according to Set $2(p<0,05)$. 
Aydın, E. M., Uçan, Y., \& Yarar, H. (2017). The acute effect of static stretching between sets on the number of repetitions performance in resistance training. Journal of Human Sciences, 14(4), 3913-3922. doi:10.14687/jhs.v14i4.4865

Table 2. The numbers of repetitions of groups with different intensities for PD exercise

\begin{tabular}{|c|c|c|c|c|c|}
\hline Intensity & Groups & Set 1 & & Set 2 & Set 3 \\
\hline & SS & $12,22 \pm 1,72$ & & $9,22 \pm 1,20^{*}$ & 7,89土1,69*\# \\
\hline \multirow[t]{4}{*}{$10 \mathrm{RM}$} & $\Delta \%$ & & 24,55 & 14,43 & \\
\hline & NS & $11,56 \pm 1,67$ & & $10,78 \pm 1,48$ & $10,00 \pm 1,87^{*}$ \\
\hline & $\Delta \%$ & & 6,75 & 7,24 & \\
\hline & SS & $31,89 \pm 4,05$ & & $23,44 \pm 2,40 *$ & $19,00 \pm 4,30^{* \#}$ \\
\hline \multirow[t]{4}{*}{$\% 60$} & $\Delta \%$ & & 26,50 & 18,94 & \\
\hline & NS & $30,89 \pm 2,52$ & & $28,22 \pm 2,95$ & $23,89 \pm 4,05^{* \#}$ \\
\hline & $\Delta \%$ & & 8,64 & 15,34 & \\
\hline & SS & $8,22 \pm 2,22$ & & $6,11 \pm 2,37^{*}$ & $5,67 \pm 1,58^{*}$ \\
\hline \multirow[t]{3}{*}{$\% 85$} & $\Delta \%$ & & 25,67 & 7,20 & \\
\hline & NS & $7,44 \pm 1,88$ & & $7,44 \pm 1,74$ & $7,22 \pm 1,79$ \\
\hline & $\Delta \%$ & & 0,00 & 2,96 & \\
\hline
\end{tabular}

$\Delta \%$ percent change from the previous set

* There is significant difference according to Set $1(p<0,05)$.

\# There is significant difference according to Set $2(p<0,05)$.
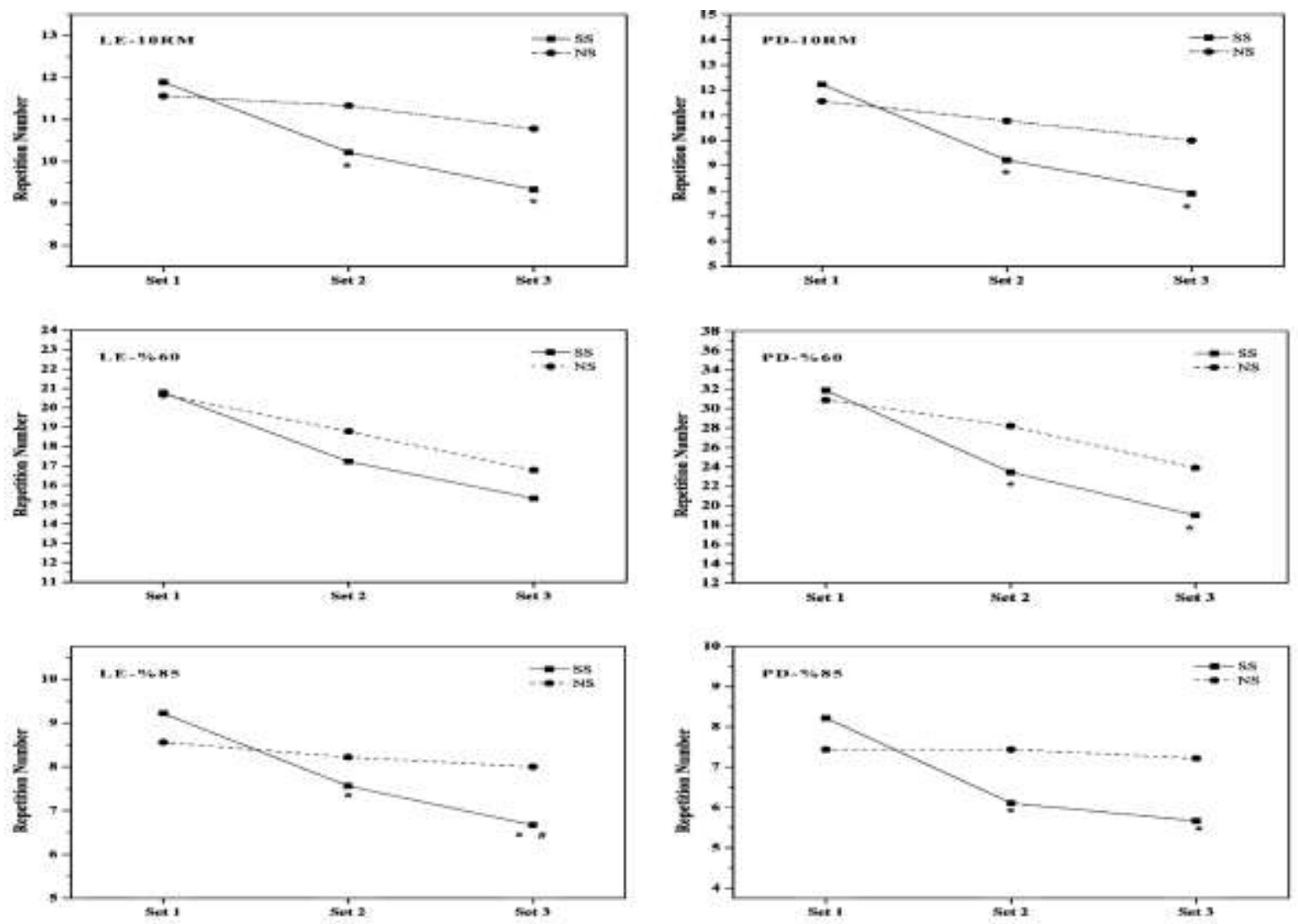

Figure 3. Changes of the number of repetitions between groups.

*There is significant difference according to Set 1

\#There is significant difference according to Set 2. 
Aydın, E. M., Uçan, Y., \& Yarar, H. (2017). The acute effect of static stretching between sets on the number of repetitions performance in resistance training. Journal of Human Sciences, 14(4), 3913-3922. doi:10.14687/jhs.v14i4.4865

\section{Discussion and Conclusion}

This study was designed to determine the effects of the interset static stretching on the number of repetition performance in resistance exercises. According the results of this study after static stretching, the number of repetitions on set 1 is higher than the other sets for PD exercise at all intensities. However, the number of repetitions after static stretching on set 1 is higher only at $10 \mathrm{RM}$ and $\% 85$ intensities for LE exercise. Interset static stretching has negative effects for PD exercises at all intensities while it has negative effects for LE at 10RM and $\% 85$ intensities.

Few studies have examined the effects of interset stretching on the number of repetitions performance so far. Arazi et al. (2015) reported static and dynamic stretching between sets has no effects on repetition performance for trained male bodybuilders. García-López et al. (2010) investigated the effects of static and ballistic stretching between sets on acceleration-deceleration and lifting velocity profiles and number of repetitions performance for bench press exercise. The results of their study showed that there were decreases in the number of repetitions for 3 treatments. However there was no significant difference between treatments. Nasiri et al. (2013) found that there was less decrease in the number of repetitions after dynamic stretching compared to passive rest between sets for untrained men at \%75 intensity of 1RM. Nasiri et al. (2011) investigated the effect of dynamic stretching between 3 consecutive sets with different rest duration on repetition performance for bench press exercise at $\% 50$ and $\% 75$ of $1 \mathrm{RM}$ intensity in untrained men. Researcher reported that both intensities and rest durations using dynamic stretching between sets resulted in higher repetition compared to passive rest for two intensities and two rest interval durations.

It has been suggested that neural and mechanical factors responsible for the decrement of muscular performance after static stretching (Ogura et al., 2007; Paradisis et al., 2014). Stiffer musculotendinous unit (MTU) more effective to force generated by muscles transmitted to skeletal system than compliant MTU (Kokkonen et al., 1998). Stored elastic energy is a function of MTU stiffness (Shorten, 1987). Kubo et al. (2001) reported that the 10 min static stretching decreased the stiffness of the tendon structure. Because of static stretching reduces the stiffness of MTU, stored and used elastic energy after static stretching less than the stiffer MTU (Sayers et al., 2008). Also stretching exercises increase in muscle compliance which may limit the more cross bridge coupling thus force production capacity of muscle decreases after stretching (Rubini et al., 2007). Neurologically, static stretching may cause decrease in muscle activation (Hough et al., 2009). Fowles et al. (2000) reported that motor unit activation significantly decreased after prolonged (30 min) stretching. Motor unit activation had recovered by 15 min while maximum voluntary contraction depressed up to $60 \mathrm{~min}$. Therefore, changes in the mechanical properties of the MTU could be responsible for the decrease in muscle strength rather than neural factors.

In summary, the current study showed that static stretching between three consecutive sets affected negatively the numbers of repetitions for upper and lower body resistance exercises with different intensities. It could be noted that both the mechanical and neurological factors may be responsible for the decrease in the number of repetitions after static stretching.

\section{References}

Ahtiainen, J. P., Pakarinen, A., Alen, M., Kraemer, W. J., \& Häkkinen, K. (2005). Short vs. long rest period between the sets in hypertrophic resistance training: influence on muscle strength, size, and hormonal adaptations in trained men. The Journal of Strength and Conditioning Research, 19(3), 572-582.

American College of Sports Medicine. (2011). Position stand: Quantity and quality of exercise for developing and maintaining cardiorespiratory, musculoskeletal, and neuromotor fitness in apparently healthy adults: guidance for prescribing exercise. Medicine and Science in Sports Exercise, 43, 1334-1359. 
Aydın, E. M., Uçan, Y., \& Yarar, H. (2017). The acute effect of static stretching between sets on the number of repetitions performance in resistance training. Journal of Human Sciences, 14(4), 3913-3922. doi:10.14687/jhs.v14i4.4865

Arazi, H., Nasiri, R., Jahanmahin, M., \& Falahati, A. (2015). Comparison of the effect of interset dynamic and static stretching on the upper and lower body performance of male bodybuilders. Facta Universitatis, Series: Physical Education and Sport, 13(3), 329-339.

Blazquez, I. N., Warren, B. L., O’Hanlon, A. M., \& Silvestri, L. R. (2013). An adequate interset rest period for strength recovery during a common isokinetic test. The Journal of Strength and Conditioning Research, 27(7), 1981-1987.

Boroujerdi, S. S., \& Rahimi, R. (2008). Acute GH and IGF-I responses to short vs. long rest period between sets during forced repetitions resistance training system. South African Journal for Research in Sport, Physical Education and Recreation, 30(2), 31-38.

Bottaro, M., Martins, B., Gentil, P., \& Wagner, D. (2009). Effects of rest duration between sets of resistance training on acute hormonal responses in trained women. Journal of Science and Medicine in Sport, 12, 73-78.

Brzycki, M. (1993). Strength testing-predicting a one-rep max from reps-to-fatigue. Journal of Physical Education, Recreation and Dance, 64(1), 88-90.

Buresh, R., Berg, K., \& French, J. (2009). The effect of resistive exercise rest interval on hormonal response, strength, and hypertrophy with training. The Journal of Strength and Conditioning Research, 23(1), 62-71.

Cornwell, A., Nelson, A. G., \& Sidaway, B. (2002). Acute effects of stretching on the neuromechanical properties of the triceps surae muscle complex. European Journal of Applied Physiology, 86, 428-434.

Evangelista, R., Pereira, R., Hackney, A. C., \& Machado, M. (2011). Rest interval between resistance exercise sets: length affects volume but not creatine kinase activity or muscle soreness. International Journal of Sports Physiology and Performance, 6(1), 118-127.

Evetovich, T. K., Nauman, N. J., Conley, D. S., \& Todd, J. B. (2003). Effect of static stretching of the biceps brachii on torque, electromyography, and mechanomyography during concentric isokinetic muscle actions. The Journal of Strength and Conditioning Research, 17(3), 484-488.

Fowles, J. R., Sale, D. G., \& MacDougall, J. D. (2000). Reduced strength after passive stretch of the human plantarflexors. Journal of Applied Physiology, 89, 1179-1188.

García-López, D., De Paz, J. A., Moneo, E., Jiménez-Jiménez, R., Bresciani, G., \& Izquierdo, M. (2007). Effects of short vs. long rest period between sets on elbow-flexor muscular endurance during resistance training to failure. The Journal of Strength and Conditioning Research, $21(4), 1320-1324$.

García-López, D., Izquierdo, M., Rodríguez, S., González-Calvo, G., Sainz, N., Abadía, O., \& Herrero, A. J. (2010). Interset stretching does not influence the kinematic profile of consecutive bench-press sets. The Journal of Strength and Conditioning Research, 24(5), 13611368.

Hill-Haas, S., Bishop, D., Dawson, B., Goodman, C., \& Edge, J. (2007). Effects of rest interval during high-repetition resistance training on strength, aerobic fitness, and repeated-sprint ability. Journal of Sports Sciences, 25(6), 619-628.

Hough, P. A., Ross, E. Z., \& Howatson, G. (2009). Effects of dynamic and static stretching on vertical jump performance and electromyographic activity. The Journal of Strength and Conditioning Research, 23(2), 507-512.

Kistler, B. M., Walsh, M. S., Horn, T. S., \& Cox, R. H. (2010). The acute effects of static stretching on the sprint performance of collegiate men in the 60 -and $100-\mathrm{m}$ dash after a dynamic warm-up. The Journal of Strength and Conditioning Research, 24(9), 2280-2284.

Kokkonen, J., Nelson, A. G., \& Cornwell, A. (1998). Acute muscle stretching inhibits maximal strength performance. Research Quarterly for Exercise and Sport, 69(4), 411-415.

Kraemer, W. J., \& Ratamess, N. A. (2004). Fundamentals of resistance training: progression and exercise prescription. Medicine and Science in Sports and Exercise, 36(4), 674-688. 
Aydın, E. M., Uçan, Y., \& Yarar, H. (2017). The acute effect of static stretching between sets on the number of repetitions performance in resistance training. Journal of Human Sciences, 14(4), 3913-3922. doi:10.14687/jhs.v14i4.4865

Kubo, K., Kanehisa, H., Kawakami, Y., \& Fukunaga, T. (2001). Influence of static stretching on viscoelastic properties of human tendon structures in vivo. Journal of Applied Physiology, 90(2), 520-527.

Miranda, H., Fleck, S. J., Simão, R., Barreto, A. C., Dantas, E. H., \& Novaes, J. (2007). Effect of two different rest period lengths on the number of repetitions performed during resistance training. The Journal of Strength and Conditioning Research, 21(4), 1032-1036.

Nasiri, R., Damirchi, R., \& Mirzaei, B. (2011). The effect of duration and type of rest interval between sets with low and moderate intensities on the volume of bench press in untrained men. Researcher in Sport Science Quarterly, 2(2), 25-33.

Nasiri, R., Damirchi, D., Mirzaei, B., \& Jahanmahin, M. (2013). Comparison the effect of duration and type of rest intervals on sustainability of leg press repetitions in untrained men. International Journal of Sport Studies, 3(8), 886-892.

Nelson, A. G., Driscoll, N. M., Landin, D. K., Young, M. A., \& Schexnayder, I. C. (2005). Acute effects of passive muscle stretching on sprint performance. Journal of Sports Sciences, 23(5), 449-454.

Ogura, Y., Miyahara, Y., Naito, H., Katamoto, S., \& Aoki, J. (2007). Duration of static stretching influences muscle force production in hamstring muscles. The Journal of Strength and Conditioning Research, 21(3), 788-792.

Paradisis, G. P., Pappas, P. T., Theodorou, A. S., Zacharogiannis, E. G., Skordilis, E. K., \& Smirniotou, A. S. (2014). Effects of static and dynamic stretching on sprint and jump performance in boys and girls. The Journal of Strength and Conditioning Research, 28(1), 154-160.

Pinto, M. D., Wilhelm, E. N., Tricoli, V., Pinto, R. S., \& Blazevich, A. J. (2014). Differential effects of 30-vs. 60-second static muscle stretching on vertical jump performance. The Journal of Strength and Conditioning Research, 28(12), 3440-3446.

Rahimi, R. (2005). Effect of different rest intervals on the exercise volume completed during squat bouts. Journal of Sports Science and Medicine, 4, 361-366.

Rahimi, R., Qaderi, M., Faraji, H., \& Boroujerdi, S. S. (2010). Effects of very short rest periods on hormonal responses to resistance exercise in men. The Journal of Strength and Conditioning Research, 24(7), 1851-1859.

Ramírez-Campillo, R., Andrade, D. C., Álvarez, C., Henríquez-Olguín, C., Martínez, C., BáezSanMartín, E., Silva-Urra, J., Burgos, C., \& Izquierdo, M. (2014). The effects of interset rest on adaptation to 7 weeks of explosive training in young soccer players. Journal of Sports Science and Medicine, 13(2), 287-296.

Ratamess, N. A., Falvo, M. J., Mangine, G. T., Hoffman, J. R., Faigenbaum, A. D., \& Kang, J. (2007). The effect of rest interval length on metabolic responses to the bench press exercise. European Journal of Applied Physiology, 100(1), 1-17.

Rhea, M. R., Alvar, B. A., \& Burkett, L. N. (2002). Single versus multiple sets for strength: a metaanalysis to address the controversy. Research Quarterly for Exercise and Sport, 73(4), 485-488.

Richmond, S. R., \& Godard, M. P. (2004). The effects of varied rest periods between sets to failure using the bench press in recreationally trained men. The Journal of Strength and Conditioning Research, 18(4), 846-849.

Rodrigues, B. M., Dantas, E., de Salles, B. F., Miranda, H., Koch, A. J., Willardson, J. M., \& Simão, R. (2010). Creatine kinase and lactate dehydrogenase responses after upper-body resistance exercise with different rest intervals. The Journal of Strength and Conditioning Research, 24(6), $1657-1662$.

Rubini, E. C., Costa, A. L., \& Gomes, P. S. (2007). The effects of stretching on strength performance. Sports Medicine, 37(3), 213-224.

Sayers, A. L., Farley, R. S., Fuller, D. K., Jubenville, C. B., \& Caputo, J. L. (2008). The effect of static stretching on phases of sprint performance in elite soccer players. The Journal of Strength and Conditioning Research, 22(5), 1416-1421. 
Aydın, E. M., Uçan, Y., \& Yarar, H. (2017). The acute effect of static stretching between sets on the number of repetitions performance in resistance training. Journal of Human Sciences, 14(4), 3913-3922. doi:10.14687/jhs.v14i4.4865

Schoenfeld, B. J., Ratamess, N. A., Peterson, M. D., Contreras, B., Sonmez, G. T., \& Alvar, B. A. (2014). Effects of different volume-equated resistance training loading strategies on muscular adaptations in well-trained men. The Journal of Strength and Conditioning Research, 28(10), 2909-2918.

Senna, G., Salles, B. F., Prestes, J., Mello, R. A., \& Roberto, S. (2009). Influence of two different rest interval lengths in resistance training sessions for upper and lower body. Journal of Sports Science and Medicine, 8, 197-202.

Shorten, M. R. (1987). Muscle elasticity and human performance. In Current Research in Sports Biomechanics (Vol. 25, pp. 1-18). Karger Publishers.

Silva, L. E., Pereira, R., Rodrigues, V. C., Silva, P. A., Silva, K. M., \& Machado, M. (2010). Length of rest interval between resistance exercise sets: performance and inter-individual variability of CK activity. Journal of Musculoskeletal Research, 13(04), 187-195.

Souza, A. C., Melibeu Bentes, C., Freitas de Salles, B., Machado Reis, V., Vilaça Alves, J., Miranda, H., \& Silva Novaes, J. D. (2013). Influence of inter-set stretching on strength, flexibility and hormonal adaptations. Journal of Human Kinetics, 36, 127-135.

Willardson, J. M., \& Burkett, L. N. (2005). A comparison of 3 different rest intervals on the exercise volume completed during a workout. The Journal of Strength and Conditioning Research, 19(1), 23-26.

Willardson, J. M., \& Burkett, L. N. (2006a). The effect of rest interval length on the sustainability of squat and bench press repetitions. The Journal of Strength and Conditioning Research, 20(2), 400403.

Willardson, J. M., \& Burkett, L. N. (2006b). The effect of rest interval length on bench press performance with heavy vs. light loads. The Journal of Strength and Conditioning Research, 20(2), 396-399.

Willardson, J. M., \& Burkett, L. N. (2008). The effect of different rest intervals between sets on volume components and strength gains. The Journal of Strength and Conditioning Research, 22(1), 146-152.

Young, W. B., \& Behm, D. G. (2003). Effects of running, static stretching and practice jumps on explosive force production and jumping performance. Journal of Sports Medicine and Physical Fitness, 43(1), 21-27. 